\title{
Las dimensiones de la identidad nacional
}

\author{
Norma Meneses Tutaya \\ Departamento Académico de Lingüistica \\ "Ama pinqapakunkichu, pullirasniyuq awilaykimantapas, \\ lirpupi uyaykimantapas". Mama Paulinaymanta
}

\section{Introducción}

El tema de la identidad en nuestro país es uno de los más gravitantes a lo largo de nuestra historia moderna. Se inicia desde el momento mismo en que se produce la conquista.

En los últimos años, tanto por la conmemoración de cinco siglos del llamado "Encuentro de dos mundos", como por la cercanía del nuevo milenio, este tema de la identidad nacional ha tomado unamayor impulso. Es terrible advertir que ya iniciado el tercer milenio y tras casi doscientos años de independencia aún no hemos llegado a la madurez de saber quiénes somos.

Otra situación que contribuye a poner al orden del día la discusión del tema de la identidad es laipresente etapa de la historia-de la humanidad, la de la globalización del capitalismo financiero internacional que ha traido consigo la globalización de la ideología capitalista occidental cuya característica fundamental es el consumismo. Esta percepción ideológica pretende constituirse en una suerte de pancultura mundial impuesta por los medios tecnológicos más modernos hasta ahora desarrollados. Frente a la perspectiva de la disolución de las culturas particulares en este manto cultural universal uniformador surgen, entre otras, las resistencias culturales. Se fortalecen las demandas de reivindicación cultural, lingüistica y racial; y se estudian las salidas frente a un planeta ideológicamente homogeneizado y dominado por el imperio del capitalismo internacional.

Por otro lado, la revisión semántico-semiótica de los planteamientos de numerosos y calificados intelectuales de nuestro pais - provenientes de diferentes especialidades del saber y las artes y de las diferentes canteras políticoideológicas- nos ha permitido arribar a las siguientes conclusiones: 
1. Los términos de indio, cholo, peruano, blanco, mestizo, raza, cultura, Iengua, y otros, relativos al tema de la identidad trasuntan una imprecisión semántica donde los rasgos semánticos de estos conceptos se entrecruzan sin establecerse una clara definición de los mismos.

2. La mayoría de los discursos acerca de la identidad parten de la premisa indiscutible de que el Perú es una sociedad dual: una sociedad de blancos y mestizos frente a una sociedad de indios. Esta propuesta teórica, nos parece, ideológicamente motivada.

3. En la actualidad existe una corriente muy fuerte, el discurso de la diversidad, que señala el lema de "la unidad en la diversidad" como solución para el problema de la identidad en el país. Es un planteamiento que se afianza en una visión postmodernista que relativiza todo discurso objetivo y se pone en duda la posibilidad de una cultura nacional. Este discurso asume que el Perú es de una diversidad absoluta en el ámbito racial, cultural y lingüístico y hay que respetarlo como tal. Esta premisa nos parece tendenciosa pues coloca en igual peso de concurrencia interna todos los elementos de cada una de estas tres dimensiones de la identidad.

Consideramos que estas conclusiones están ligadas entre sí por un mismo hilo ideológico conductor que intentaremos mostrar desde una visión personal, a guisa de hipótesis para ser corroborada o descartada; pero cuando menos, servirá para motivar una nueva mirada, indomestiza esta vez, al mismo tema de siempre.

\section{Biblioteca de Letras}

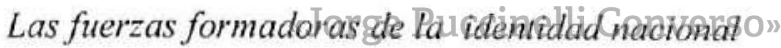

Según el etnólogo germano K. Dittmer (1968), cinco son las fuerzas o elementos formadores de la unidad étnica: el medio ambiente, la raza, el lenguaje, la asociación política y la cultura. Podemos asumir, por lo tanto, que la percepción humana de esta interrelación de elementos da lugar a una concepción mental de identificación o pertenencia a la unidad étnica. De esta concepción, se puede deducir también que, al menos, estos cinco factores constituyen las dimensiones básicas de la identidad de una nación. Es decir, que son las dimensiones geográfica, racial, lingüística, cultural y política las que configuran esencialmente a una nación.

Estas cinco dimensiones son autónomas entre sí, esto es, que no existen relaciones de determinación que conduzcan a una suerte de sinonimia entre raza y cultura ni entre lengua y cultura, y mucho menos entre raza y lengua. Estas 
dupletas han sido asumidas como entidades reales que hacen que una persona considere que si alguien es de raza india, entonces debe saber quechua; o por otro lado, si no sabe quechua, no es un auténtico representante de la cultura andina; y por último, si es de raza india, debe ser obligatoriamente miembro de una cultura andina y si es negro deberá ser un representante de la cultura afroperuana; por eso nos parece incomprensible que un indio sea un declarado criollísimo, u otras, nos sorprende muchísimo ver a un negro quimboso desenvolviéndose como de los mejores cantantes y zapateadores de huaylas, como es el caso del Chivillo de los Andes. No obstante, es necesario reconocer que existe una estrecha relación entre algunas de ellas como en el caso de lengua y cultura, y raza y cultura. En el primer caso, es innegable que la lengua es el contenedor principal y vehículo primigenio de la cultura; mas esto, no nos debe conducir a identificarlas en una sola dimensión. Por otro lado, históricamente, la raza estaba ligada a una conjunto cultural puesto que la posibilidad de grandes migraciones transcontinentales eran excepcionales. Sin embargo, con el desarrollo de la tecnologia del transporte marítimo, terrestre y aéreo, a través de los cinco últimos siglos de la historia humana, el cual ha posibilitado las grandes migraciones raciales_recuérdese el execrable comercio de los esclavos africanos_ del mundo moderno, podemos observar que esta relación entre raza y cultura queda bastante debilitada y no pueden ser reducidas a una dimensión única, y menos de indole genética.

Extrapolando estas dimensiones al estudio de la identidad nacional de nuestro país, podemos encơontranencel Rerú actua las siguientes dimensiones.

\section{"Jorge Puccinelli Converso»}

\section{La dimensión geográfica}

Está definida por el medio físico y social en el que transcurre la vida de una comunidad humana. El medio físico está dado por el territorio que ocupa con todas sus características geológicas y bióticas. En el caso del Perú, su territorio comprende alrededor de $1,285,215 \mathrm{~km} 2$, lo que lo ubica en el tercer país más extenso en Sudamérica. La particularidad geográfica del Perú es su megadiversidad ecológica: posee 86 de los 104 climas existentes en todo el planeta. No obstante, este dato no nos debe conducir a imaginarnos que todos estos hábitat tienen igual participación en el conjunto total. De entre ellos, lo mayoritario son los de tipo montañoso, pues lo preeminente en nuestra geografía es la Cordillera de Los Andes. Desde una mirada objetiva, podríamos observar que lo denominado como Costa y Selva, fundamentalmente, son las 
estribaciones occidentales y orientales de la gran cordillera, pues no es mucho lo que poseemos de llano amazónico, es por ello quẹ en lengua quechua yunka significa tanto las estribaciones de la denominada zona Yunga de la región occidental de Los Andes como la región oriental denominada Selva Alta.

El medio social está constituido por el conjunto de comunidades vecinas aliadas o enemigas con las que delimita una comunidad. La diferenciación está dada por la autopercepción de sentirse diferentes de los otros y la corroboración de esta percepción por parte de los otros grupos. Es decir, que no sólo basta con autorreconocernos distintos a los otros; sino, también, que los otros nos perciban distintos a ellos. En este último aspecto, es difícil señalar de manera precisa en qué nos diferenciamos de nuestros vecinos países de habla hispana y más aún con aquellos que además tienen una cultura y un pasado histórico común con nosotros como son Bolivia y Ecuador. Si se les pidiera a un grupo de peruanos, bolivianos y ecuatorianos, todos andinos y que desconocen su adscripción territorial, que señalaran cuál es la nacionalidad de sus respectivos vecinos muy pocos podrían acertar dada su similitud racial, cultural y lingüística. A este respecto, es interesante recordar el cuento de Julio Ramón Ribeyro sobre dos soldados heridos, uno ecuatoriano y el otro peruano, cuya indiferenciación era total una vez despojados del uniforme. Esta situación nos conduce a concluir que estas tres dimensiones no tienen necesariamente una adscripción territorial congruente con la adscripción territorial política. Es decir, trascienden las fronteras de los estados.

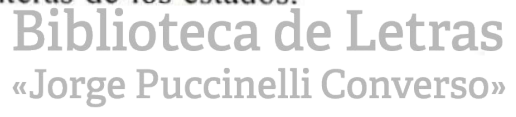

\section{La dimensión racial}

El factor racial es un elemento importante a tomar en cuenta. Aunque éste es un tema muy espinoso y que se trata siempre de soslayar en cualquier ensayo sesudo, es necesario aventurarse a hablar sobre él. La población que conforma una unidad étnica presenta rasgos fenotípicos comunes que conducen a tipificarla como perteneciente a cualquiera de los cuatro grupos humanos existentes en el planeta: la denominada raza amarilla o, técnicamente, la mongoloide dentro de la cual se encuentra la rama india o cobriza, la raza aria o blanca, la raza africana o negra y la raza australiana. Estos troncos fenotípicos, como lo señala la antropología física, están definidos en términos de rasgos físicos que atañen más a la morfología del cráneo, la forma del rostro y las partes del cuerpo y otros aspectos fisiológicos, que a la coloración de la piel. Sin embargo, en nuestro medio, todo el concepto de raza se ha reducido semánticamente a este último 
rasgo que, científicamente, es el menos gravitante. Esta concepción reduccionista es el rasgo semántico que está presente en toda clasificación espontánea que hacen las personas acerca de personajes de la televisión. Al preguntarle a los niños de un colegio nacional que mencionaran a personajes conocidos que ellos clasificasen como blancos, ellos catalogaron como tales a Mónica Delta, Susy Díaz, Mónica Sánchez, Christian Maier y Janet Barboza. Algunos de los mencionados, si se les preguntara si se consideran de raza blanca, no se sentirían en capacidad de asumir tal clasificación plenamente.

Sobre la dimensión racial, el discurso de la diversidad señala la característica multirracial como preeminente en nuestro país. Esta caracterización es una verdad a medias. El nuestro es un país donde la mayoría de la población es de raza india, con la importante presencia del grupo mestizo y las minorías de raza blanca, amarilla y negra. Y es precisamente esta configuración la que la intelectualidad oficial niega y pretende presentarnos dos miradas diferentes; por un lado, un país mayoritariamente compuesto de "todas las sangres"; o por el contrario, un país donde el grupo mayoritario es el mestizo. Ambas enfoques, si bien distintos, sólo pretenden ocultar una realidad innegable: el predominio de lo indígena. Definitivamente, el proceso de mestizaje ha sido constante e intenso y también doloroso; pero no se trata de un mestizaje half and half entre lo blanco y lo indio; la historia de las migraciones en el país evidencia que esta situación es imposible. El grueso de nuestro mestizaje se inclina hacia el ingrediente indígena. Es en el plasma indígena donde se refunden todas las demás sangrés. Y es el fenotipe indigena el que históricamente existió, existe y existirá en el futuro. Recuerdo a un anciano criollo y terrateniente ayacuchano predicarles a sus nietos de la necesidad de no mezclarse con los "indios crecidos", o "cholos" porque "desde que se fueron los españoles, la sangre de la madre patria es poca en este pais y si no la preservamos puede desaparecer". No olvidemos que para los administradores coloniales "cholo" era un equivalente a mulato "cuarterón", es decir, poseedor de una cuarta parte de español: el hijo de la unión de un mestizo(a) con un indio(a). Este es el temor real que subyace en el inconsciente colectivo criollo y mestizo escondido bajo frases como "salto pa "tras" y que resulta difícil reconocerlo como tal. Es, también, la raíz de nuestra curiosa discriminación racial, donde los criollos y mestizos son muchas veces más racistas entre sí -sorprendentemente, en el propio entorno familiar-y contra los indios y los negros, que los pocos blancos que existen en nuestro país. Hay una permanente medición del grado de blanqueamiento que tiene la piel del prójimo. A esto se aúna una serie de estrategias sociales que conducen al mismo fin como son el mayor capital económico y el nivel educativo alcanzados. 
El Perú oficial de hoy debe asumir esta realidad indigena mayoritaria y sentar sobre ella las bases de nuestra identidad. Esto implica que los del grupo mestizo debemos asumir que nuestro mestizaje es mayormente indígena y que no somos más que parte del contimuum indigena. Es decir, que somos los mestizos los que debemos asumir, valientemente, nuestra identidad indomestiza frente a nuestra imagen en el espejo, así como, en el espejo de nuestros abuelos, padres, hijos y nietos. Para la gran mayoría de la población, esta verdad y la aceptación de nuestro origen indigena será una liberación, nos devolverá nuestra autoestima, nos reinsertará en nuestra historia y en nuestras raices ancestrales. Y lo más importante aún, permitirá reestablecer la unidad entre lo indio y lo mestizo.

A comienzos del siglo XX, Ricardo Palma, perspicaz criollo de origen mulato y dueño de una gran intuición lingüística, propuso una salida feliz ante el empantanamiento semántico de la diversidad de términos raciales como: cholo, indio, criollo, mestizo, mulato, etc., que expresaba el desconcierto ontológico de la naciente República; a la vez, que establecía los fundamentos de la ideología criolla: "en este pais quien no tiene de jnga, fiene de mandinga". Frase que, si la analizamos correctamente, no resulta inocente y mucho menos, integradora. Establece positivamente el reconocimiento del mestizaje de las clases criollas dominantes del país: "el que no tiene de inga, tiene de mandinga"; pero a su vez señala la orientación del mismopor el recurso de la omisión. El factor no nombrado, lo blanco, es lo gravitante y más importante en estas mixturas que constituyen las clases dominantes. Está es a basedel aftanzamiento de la concepción de una sociedad dual heredadpdesdâd Virreinato:_a república de los blancoscriollos y la república de los indios. La historia de la frustración de una propuesta nacional autóctona fue ideológicamente sellada con ello. Al parecer éste es el origen de diferenciación semántica que persiste en el imaginario colectivo actual entre lo mestizo y lo criollo y que señala las dos direcciones de la identidad racial, a futuro, para las clases dominantes. Si bien ambos términos reconocen la mezcla racial como su fundamento, las fórmulas de constitución son diametralmente opuestas. Lo mayoritario en lo criollo es el aporte racial blanco; en tanto que en lo mestizo lo gravitante es la base india, situación que puede extenderse al ámbito cultural.

En este tercer milenio, se alza frente a nosotros una nueva oportunidad de integración; sin embargo, existe un peligro de sesgamiento ideológico que podría crearnos una nueva frustración histórica. Se trata de la percepción de una alternativa mediatizadora: "No somos más indios ni más blancos, somos una 
nueva raza, que tiene el aporte equitativo de las dos razas mayores". Esta opción, que de antemano es irreal porque el mestizaje no es una raza, sólo puede aparentar una verdad si es aplicada algún sector minoritario de mestizos que hacen de su árbol genealógico uno de pedigri racial; no es cierta ni refleja el verdadero movimiento del mestizaje en el Perú. Constituye la misma propuesta de Palma, esta vez, aplicada a toda la nación. De triunfar esta percepción, nuevamente se reafirmaria la percepción dualista del país: una república de mestizos frente a una república de indios. La diferencia fundamental es que ahora estos indios no serían los indios analfabetos, pobres y enviciados de comienzos de la República. Hay cada vez un rumor creciente de autopercepción de indianidad y de aceptación y orgullo de esta identificación que, en muchos casos, parece ser más cultural que racial. Para el grupo mestizo, ésta es la oportunidad de integrarnos, conscientemente, asumiendo NUESTRO INDOmestizaje y reformulando la frase de Palma: "en nuestro Perú de hoy, la base predominante es indígena, el mestizaje es creciente y el que no tiene de godo, ya tiene de mandinga, ya tiene de chino, o ya tiene un poco de todo". Esta opción es más realista y es el fundamento de lo que ahora se está construyendo espontáneamente en nuestra sociedad actual bajo la denominación de "cholitud" o "choledad".

\section{La dimensión lingüistica}

El discurso de la diversidad pondera la característica multilingüe de nuestro país basándose en gos estudios objetivos deda lingǘstica peruana. Existen en nuestro territorio más de cuarenta lenguas diferentes, incomprensibles entre sf, agrupadas en diecinueve familias lingíisticas. Sin embargo, ésta también es una verdad a medias. Lo cuantitativo es que la mayoría de estas lenguas, agrupadas en dieciséis familias lingulsticas, se ubican en la Selva y en conjunto constituyen algo más de 150,000 hablantes. Las dos familias lingioisticas andinas, quechua y aimara, presentan alrededor de 7 millones y 500,000 hablantes, respectivamente, incluyendo en estos últimos, los 1500 hablantes de jaqaru. Sin embargo, es el castellano, perteneciente a la familia latina, la lengua mayoritariamente hablada en el Perú actual con casi 26 millones de hablantes de una población aproximada de 28 millones. Asimismo, esto implica que el otro fenómeno oculto es el del crecimiento del bilingùismo en el Perú, pues únicamente un millón y medio de compatriotas son monolingdes en lenguas nativas y algo más de siete millones son bilingues vernáculo-castellano. 
Todos los datos anteriores son números aproximados debido a que los censos nacionales no han tenido interés en recoger estos datos, y por otro lado, por la tendencia a ocultar los datos sobre conocimientos de lenguas nativas por la población, en vista del bajo prestigio que poseen y el estigma social que aún significan. Comparando estas cifras con las del censo del año 1940, observamos que el Perú pasó de ser un país de lengua mayoritariamente indígena ( $70 \%$ de su población era monolingüe quechua), a uno de lengua mayoritariamente castellana ( $70 \%$ de su población es monolingüe castellana). Este es el proceso de extinción de las lenguas nativas que a su vez ha conducido al pais hacia un nuevo escenario lingüistico cuyas dimensiones aún desconocemos: la diglosia interna al castellano. Sin embargo, cabe puntualizar que existe una número significativo de bilingües, muchísimos con nivel educativo superior, que constituyen un recurso humano invalorable para intentar revertir este proceso de extinción de nuestro acervo lingüístico.

Frente a este panorama, es necesario que las politicas educativas contemplen no sólo la educación bilingüe de mantenimiento dirigida a las cada vez minoritarias comunidades indigenas monolingües, sino simultáneamente, se realice una fuerte inversión en la educación bilingüe de recuperación, que como su denominación lo indica permita a las poblaciones andinas y amazónicas, de carácter rural y urbana, tanto bilingües o monolingües castellanas, lograr recuperar y ampliar el uso integralde sus lenguas ancestrales. Es decir, asumir que el bilingüismo castellano-lengua nativa es un derecho lingüistico de los pueblos indigenas e indomestizos. La politica de reivindicación lingüística, afrontada desde estos dos frentes, conducira a alcanzar un cafo ânhelo de los lingüistas:

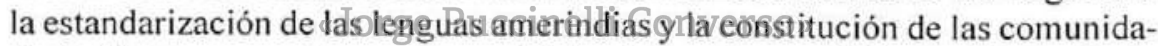
des indigenas y mestizas en comunidades integralmente bilingües interculturales y letradas.

\section{La dimensión cultural}

En esta dimensión, el discurso de la diversidad, pone el acento en el carácter pluricultural de nuestro país, lo cual es cierto en líneas generales pues existen las diversas culturas amazónicas, la cultura andina quechua, aimara y jaqaru, la cultura criolla, la cultura afroperuana, la cultura sino peruana. No obstante, una vez más, se pretende mostrarnos el bosque para no ver el árbol. El peso de las múltiples culturas en nuestro país es relativo y lo que no debemos dejar soslayar es que en nuestro país lo mayoritario, sin duda alguna, es la cultura andina en todas sus variantes. Esta aseveración, no nos debe conducir 
a señalar que la necesidad de reconocer políticamente esta situación tiene que producir la desaparición o minimización de las otras culturas, Todo lo contrario. Se pretende que se le reconozca a la cultura andina su sitial preeminente frente a la cultura criolla, la que detentó el poder político del Estado arrogándose la representatividad absoluta de todo el pais e intentando homogeneizarlo a su imagen y semejanza; sin que esto signifique que sea ta cultura andina la que arrolle in vindicta a la cultura criolla junto con las demás.

Se entiende por cultura andina al producto cultural de base indigena andina (cuyas lenguas fueron el quechua, el aimara, el jaqaru y las otras lenguas precolombinas ya extintas) que ha evolucionado a través de los siglos incorporando y reinterpretando los aportes culturales de los otros gnupos (hispano, africano, amazónicos y oriental) con los cuales entró en contacto. Las variantes que se pueden observar se deben fundamentalmente a los porcentajes de estas mixturas en el contenido mayoritariamente indigena, asi como a las diferencias entre lo rural y lo urbano. Sin embargo, esto no quiere decir que la cultura andina es una cultura precolombina sin más ni más. Lo real es que la fuerza de los procesos históricos de dominio y sojuzgamiento politico y económico han dejado huellas que se han decantado en un largo proceso de mestizaje cultural donde el acento sigue ubicándose en lo indigena. Es, precisamente, esta base indigena lo que nos permite aseverar que en gran medida la cultura andina es, diacrónicamente, un continuum cultural del Perú precolombino ancestral. El parangón que podemos ofrecer es el de la evolución de las lenguas. Si bien el castellano actual, comparado con elcastellano del siglo.XII del Mio Cid no es el mismo por las notorias divergencias cstructurales, tampoco se puede negar que se trata de la misma lengua, en sus aspectos fundamentales. Otro tanto, se puede decir del inglés actual y el inglés del siglo XIV de las obras de Chaucer.

La pregunta que resta hacernos es: ¿cuáles son esos aspectos fundamentales que permiten establecer el eje del continuum cultural andino? Consideramos que éstos no tienen que ver con los aspectos materiales y directamente perceptibles de la cultura como son las costumbres, la vestimenta, las artes, la economía, etc.; sino más bien, con los aspectos más entrafíables y abstractos como son jos fundamentos ideológico-conceptuales. Aquellos, que algunos estudiosos denominan postulados culturales. J. Golte la denomina "la mochila cultural" con la que los migrantes andinos enfrentan los nuevos escenarios a los que se ven expuestos. Entre estos postulados fundamentales se pueden seffalar: la laboriosidad, la solidaridad de grupo, la reciprocidad obligatoria no necesariamente inmediata en el tiempo, el ascetismo o frugalidad, la organiza- 
ción jerárquica, la religiosidad animista, la sistematización del manejo de la diversidad de entornos, la visión prospectiva basada en la concepción de que el pasado está frente a nosotros "ñawpaq" y que es construido día a dia en el presente para formar el futuro que está detrás "qipa", el mandato generacional de progreso. Empero, es necesario precisar que cada uno de estos postulados culturales no son de carácter privativo de la cultura andina, sino que lo propio es únicamente la sistematización de las mismas.

Una educación formal del Perú actual deberá afrontar el reto de la interculturalidad accediendo al estudio y la comprensión de los postulados culturales de las culturas de nuestro país y no únicamente de sus manifestaciones culturales externas. Asimismo, hay necesidad de que este estudio se realice no sólo desde una perspectiva cartesiana de la cultura en sí misma como si se tratara de un ente absolutamente autodefinible, sino, además, comprender que un fenómeno propio del desarrollo cultural son los contactos culturales. En el Perú de hoy, estos contactos se han intensificado y profundizado originando, en algunos estratos sociales y en algunas regiones más que en otras, una suerte de continuum cultural sincrónico entre lo andino y to criollo que algunos identifican como el "acriollamiento"; 0 en su versión venal, el "achoramiento", o desde lo criollo se denomina la "andinización" o la "cultura chicha"; o entre lo andino y lo amazónico, cuya denominación desconocemos, pero que es probable que exista. Frente a esta situación, es cada vez más evidente que necesitamos estudiarnos a nosotros mismos para, luego, poder estudiarnos unos a otros y asi poder conocernos, comprendemos grespetarnos mutuamente. Los estudiosos de la sociedad y la cultura deben necesariamente partir, primero, por auscultarse a si mismos para poder identificarse culturalmente $y$ aceptar que su mirada hacia el otro estará, necesariamente, sesgada por su perspectiva cultural. Por lo tanto, estará mucho más atento para encontrar no sólo lo particular en el otro; sino, también, lo universal en el otro, lo cual servirá a manera de un tertium comparationis que le permitirá alcanzar una relativa aproximación objetiva hacia el otro y hacia si mismo, simultáneamente.

\section{La dimensión politica}

Esta dimensión ha sido la única que conscientemente se ve reflejada en la mayoría de los peruanos, producto de la instrucción pública. Esta dada por el tipo de organización sociopolítica existente. Nuestro país por mandato de la Constitución es una República representativa que elige a sus gobernantes por 
elecciones públicas y democráticas. Al margen de cualquier cuestionamiento sobre la verdadera dimensión de su carácter democrático, nadie pone en duda la existencia del Perú como un Estado Republicano que posee un territorio, símbolos patrios y autoridades reconocidas por la jurisprudencia internacional. Sin embargo, esta homogeneidad política construida a manotazos desde el inicio de la República está empezando a ser modificada por el proceso político actual: el de la descentralización política que al parecer esta vez va "de verdad". Las recientes elecciones de autoridades regionales del año 2002 así parecen denotarlo; aunque aún falta ver la implementación del marco legal y más importante aún, el establecimiento de un marco económico-financiero claramente definido que permita el desarrollo relativamente autónomo de las nuevas regiones.

En sintesis, podemos argùir que si bien el discurso de la diversidad es una propuesta muy atrayente, halaglefia y aceptable en buena medida, no debe confundimos a la hora de realizar una visión dialéctica del Perú de hoy. Nuestro pais es uno geográficamente diverso, donde prima el carácter montafoso de la cordillera de Los Andes. Es multirracial, pero en el cual lo absolutamente predominante es lo indigena y lo indomestizo en un continuum racial. Es multilingue, mas lo mayoritario es el castellano y secundariamente es bilinglie vernáculocastellano. Es pluricultural, sin embargo, lo predominante es la cultura andina. $Y$ por último, es un Estado Republicano y Democrático que para cumplir con este último carácter deberá incorporar las demás dimensiones, cada una en su justa medida, dentro de su proyecto nacional. Es decir, para ser justos y equitativos hay necesidad de reconocen la presencia del otro no solo en cuanto es sino también en cuanto está, no sólo cualitativamente sing, además, cuantitativamente. No hacerlo ast, nos haria caer en una posición de mantenimiento del statuo quo actual del país: perennizamiento del dominio económico y sociocultural de las minorfas criollas de las diversas regiones del pais, lo que constituye el apartheid peruano mencionado alguna vez por Bryce Echenique.

La pregunta crucial es qué pasaría si no se cumpliera este camino, casi natural, hacia la "cholitud" del pais; si nuevamente el grupo cultural mestizo siguiera manteniendo el fiel de la balanza hacia el lado criollo, como antes lo hizo hacia el lado del colonizador con motivo de los levantamientos indigenas. Probablemente, se cumplirfa el anhelado suef̂o de aquellos intelectuales que con la reivindicación y fortalecimiento de los grupos étnicos minoritarios consideran que se da solución a la situación de miseria de estos pueblos y a su integración al Perú oficial, en una suerte de acogedora caridad cultural; pero lo que no advierten en su ceguera, es que en paises como los nuestros, los grupos cultu- 
rales indígenas no son minoritarios sino absolutamente mayoritarios. Piénsese en las direcciones divergentes y hasta desintegradoras que vienen tomando los indígenas y los mestizos-criollos en países como Ecuador y Bolivia. La pregunta que se hacen estos intelectuales es ¿por qué los grupos étnicos de la selva en el Perú, se unen para consolidarse como grupo étnico, los andinos no lo hacen así? La respuesta que suelen darse es que los andinos están mucho más "aculturados" y disueltos en la sociedad oficial que los otros grupos minoritarios. Particularmente, consideramos errada esta perspectiva. Creemos que se trata de la perspectiva de una hormiga parada sobre la frente de un gigante adormecido del cual apenas puede divisar la punta de la nariz. Imagínense cuando se ponga de pie... sólo esperemos que para entonces todos seamos interculturales bilingües y letrados y aprendamos a respetarnos y asociarnos para lograr el desarroIlo común.

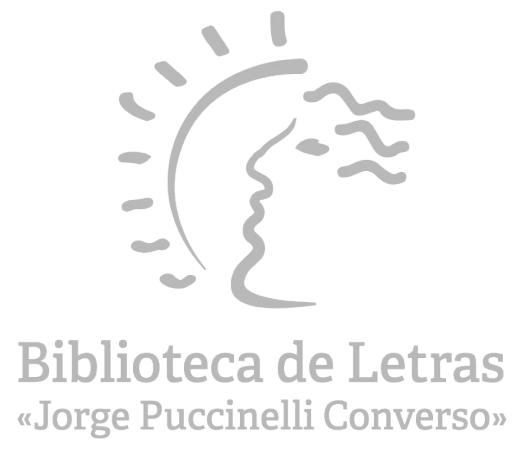




\section{BIBLIOGRAFÍA}

CONTRERAS, Carlos. Maestros, mistis e indios en el Perú rural del siglo XX, Serie Documentos de Trabajo del Instituto de Estudios Peruanos (IEP) 1996.

CORNEJO POLAR, Antonio. Literatura y sociedad en el Perú. La novela indigenista. Ed. Lasontay. Lima. 1980.

DEUSTUA, José y José Luis RENIQUE. Intelectuales, indigenismo y descentralismo en el Perú 1897-1931. CERA Bartolomé de las Casas. Cusco. 1984

DITTMER, K. Etnologia. FCE. México. 1968.

DOLLFUS, Olivier. El reto del espacio andino. IEP. Lima. 1981.

FLORES GALINDO, Alberto. Buscandorun Inca. Ed. Horizonte. Lima. 1988.

GOLTE, Jurgen. La racionalidad de la organización andina. IEP. Lima.1980.

HEISE, Maria (comp.). Interculturalidad. creación de un concepto y desarrollo de ungactitud EORTEPE-MINEDU, Lima. 2001.

IGUIÑIZ, Javier (comp.). Lacuestion agraria enefPeru. Fondo Editorial PUCP. 1983.

MALETTA, Héctor. “Perú, ¿país campesino?”, Análisis $\mathrm{N}^{\circ}$ 6, setiembre-diciembre, pp. 3-51. Lima. 1978.

MURRA, John V. Formaciones económicas y politicas del mundo andino. IEP. Lima. 1975.

RIVARA DE TUESTA, Maria Luisa. Tres ensayos sobre filosofia en el Perú. Banco Central de Reserva. Lima. 1999.

SIGNORINI, Ines. Lingua(gem) e identidade. FAEP/UNICAMP. Sao Paulo. 1998. 